\title{
COMMUNICATION PATTERN OF TRIBAL WOMEN OF ANDHRA PRADESH IN INCOME GENERATING ACTIVITIES
}

\author{
Y. UMA JYOTHI ${ }^{1} \&$ N. SUNITHA ${ }^{2}$ \\ ${ }^{I}$ P.G. Student, Department of Home Science Extension Education, \\ CCS Haryana Agricultural University, Hissar, India \\ ${ }^{2}$ Research Scholar Student, Department of Home Science Extension and \\ Communication Management, PJTSAU, Hyderabad, India
}

\begin{abstract}
The study conducted on constraints faced by tribal women income generating activities. The study was undertaken in district Srikakulam which was randomly selected out of all five districts of Andhra Pradesh having tribal population. From selected district two blocks one village from each i.e. Rajam (plain) Palakonda (hilly) were selected randomly. The results of the study revealed that information input can be inferred that non institutional sources were highly utilized for acquiring information. Regarding information processing self evolution was the most used method.The utilization of information was high as all the respondents had benefited from the information received.Information output pattern was low showing the need of government to act in spheres of credit /loan and marketing to help tribal women workers. There is also a need for institutional cosmopolite sources like village level worker, health assistant etc.To play role so that tribal women may use them as information inputs skill information and skill upgrading programme should be held for training entrepreneurs.

KEYWORDS: Tribal Women, Income Generating Activities and Communication Pattern
\end{abstract}

Received: Jul 11, 2017; Accepted: Jul 26, 2017; Published: Jul 29, 2017; Paper Id.: IJESRAUG201711

\section{INTRODUCTION}

All round development of women has become vital concern in the present times census reports reveal that, womenfrom the largest unemployed group of population.In countries like the profile of women in general,particularly tribal roles,Power and responsibilities are very distinctive.The literacy rate of tribal's is 23.63(Singh,1991). This is lower that ofgeneral population (52.21) and is lower than that of scheduled caste population (30.6). The literacy rate of tribal femaleswas 8.04 per cent in 1981 and is 14.50 per cent in 1991 which is the lowest of all social groups.It has been found thatilliteracy in tribes is positively correlated with ill health. Out of various factors,economic independence appears to be oneof the vital indicators to improve the life style of people.To accelerate the process of development this section of peopleneed to be developed by creating better economic opportunities. It is hericular problem for the government to provideadequate employment to themSelf employment to a great extent help in tackling this problem. Economic developmentcannot be brought about by a technological revolution alone. It is through timely communication of information creatinginterpersonal linkage that people tend to change their attitudes. In order to understand the communication behavior and pattern of tribal women involved in income generating activities, it is felt important to find out their media habits i.e how they are receiving information, Processing information and further, how information is being utilized in the income generating activities. 
Dhanasree, K.et.al. (2014) revealed that extent of information seeking behavior; Achievement motivation and credit orientation were found to be medium. Extent of mass media exposure is found to be low.

Rashid,M.M,et.al.(2015) revealed that the highest proportion (38.39\%) of the women beneficiaries had medium use of communication sources, Organizations engaged in extension activities should make necessary arrangements for improving the use of communication sources by them in income generating activities.

\section{METHODOLOGY}

The study was undertaken in district Srikakulam which was randomly selected out of all five districts of Andhra Pradeshhaving tribalpopulation. From Srikakulam, two blocks Seethapet (hilly) and Ganguwari Cigadam (plain) were selected randomly and from the two blocks one village from each i.e Rajam (plain) Palakonda (hilly) were selected randomly.100 tribal women respondents who were already involved in income generating activities were selected randomly personal,social,economic,psychological and communication pattern of tribal women was taken as dependent variable.

Communication pattern of tribal women was measured in terms of information input, information processing and information output.The information indices developed separately containing various sources for which the score of 3 (mostly ) 2 (sometimes ) and 1 (never) were assigned.Overall communicatio0n pattern was further quantified by summing individual score of each component (information input,processing and output )as communication pattern score of every individual.The total scores were divided inti three categories of low $(<1.66)$,medium (1.66) and (2.32) high.

\section{RESULTS AND DISCUSSIONS}

The results of the study are presented below to assess communication attern on tribal women of Andhra radish in income generating activities.

\section{Information Input Pattern}

Among non institutional sources respondents received information through family members with weighted mean score 2.94, followed by neighbors 2.74).Successful self employed women (2.65) were also utilized sometimes.The most utilized among the non institutional locatlite sources were local leaders of Mahila Mandals with weighted mean score of 2.28, while supervisors and Assistant Project Officer (APO) were the least utilized.

Table 1: Information Input Pattern of Tribal Women N=100

\begin{tabular}{|c|c|c|c|c|c|}
\hline Sources & Mostly & Some Times & Never & Weighted Mean Source & Rank \\
\hline \multicolumn{6}{|l|}{ 1.Non Institutional Sources } \\
\hline Family & 94 & 6 & - & 2.94 & I \\
\hline Successful self employed women & 65 & 35 & - & 2.65 & III \\
\hline Neighbours & 74 & 26 & - & 2.74 & II \\
\hline Overall Mean Score & & & & 2.77 & \\
\hline Overall Rank & & & & & $\mathbf{I}$ \\
\hline \multicolumn{6}{|l|}{ 2. Institutional Locality Sources } \\
\hline Local leaders of Mahila Mandal & 55 & 45 & - & 2.55 & $\mathrm{I}$ \\
\hline Sarpanch & 38 & 62 & - & 2.38 & III \\
\hline Village level Workers & 46 & 54 & - & 2.46 & II \\
\hline Overall Mean Score & & & & 2.46 & \\
\hline Overall Rank & & & & & II \\
\hline Institutional Personal/C & nopolite & & & & \\
\hline
\end{tabular}


Andhra Pradesh in Income Generating Activities

\begin{tabular}{|c|c|c|c|c|c|}
\hline School teacher & 35 & 29 & 36 & 2.28 & I \\
\hline \multicolumn{6}{|c|}{ Table 1: Contd., } \\
\hline Adult Education Teacher & 7 & 44 & 49 & 1.58 & VI \\
\hline Gram Sevika & 14 & 71 & 15 & 1.99 & $\mathrm{~V}$ \\
\hline MukhyaSevika & 19 & 67 & 14 & 2.05 & II \\
\hline Supervisor & 2 & 34 & 64 & 1.38 & VII \\
\hline Asst. Project officer & 2 & 16 & 82 & 1.20 & IV \\
\hline Bank Officials & 1 & 27 & 72 & 1.29 & III \\
\hline Overall Mean Score & & & & 1.68 & \\
\hline Over Rank & & & & & IV \\
\hline \multicolumn{6}{|c|}{ Media/Impersonal Cosmopolite Sources } \\
\hline Radio & 86 & 12 & 2 & 2.84 & I \\
\hline Television & 77 & 21 & 2 & 2.74 & II \\
\hline Film show & 8 & 56 & 36 & 1.76 & $\mathrm{~V}$ \\
\hline Demonstration & 17 & 36 & 47 & 1.70 & VI \\
\hline Exhibition/Fair & 13 & 64 & 23 & 1.90 & III \\
\hline Poster & 4 & 44 & 52 & 1.52 & VII \\
\hline Video & - & 18 & 82 & 1.18 & VIII \\
\hline Tape recorder & 10 & 57 & 33 & 1.77 & IV \\
\hline Overall mean Score & & & & 1.92 & \\
\hline Overall Rank & & & & & III \\
\hline
\end{tabular}

In media/impersonal cosmopolite sources, radio and television were the most utilized sources with 2.84 and 2.75 WMS respectively.This is in agreement with the findings of Seema (1990) that radio and television were most used to the surprise, Few respondents had never used radio and television while video was least utilized source exhibition was used sometimes as a source of the respondents, followed by tape recorder.

\section{Information Processing Pattern}

Regarding information processing self evaluation was most method with overall mean score 2.66 ranking 1 st, followed by preservation of information with 2.41 overall mean score ranked 2 nd and discussion method (2.07).

Table 2: Information Processing Pattern of Tribal Women $\mathrm{N}=10$

\begin{tabular}{|c|c|c|c|c|c|}
\hline Sources & Mostly & Sometimes & Never & $\begin{array}{l}\text { Weighted mean } \\
\text { Source }\end{array}$ & Rank \\
\hline \multicolumn{6}{|l|}{ Discussion Method } \\
\hline Family members/Elders/Relatives & 68 & 28 & 4 & 2.64 & I \\
\hline SuccesfulSelf employed women & 58 & 38 & 4 & 2.54 & II \\
\hline Sarpanch and Local Leaders of Mahila Mandal & 12 & 60 & 28 & .84 & III \\
\hline Traders & 1 & 26 & 73 & 1.28 & IV \\
\hline Overall mean Score & & & & 2.07 & \\
\hline Overall Rank & & & & & III \\
\hline \multicolumn{6}{|l|}{ Self Evaluation Method } \\
\hline Consider availability of inputs & 67 & 33 & - & 2.67 & III \\
\hline Consider economic aspects & 33 & 47 & - & 2.53 & IV \\
\hline $\begin{array}{l}\text { Consider the social and cultural compatibility } \\
\text { of innovation }\end{array}$ & 45 & 45 & - & 2.35 & $\mathrm{~V}$ \\
\hline $\begin{array}{l}\text { Consider the technical problem in learning } \\
\text { innovation }\end{array}$ & 21 & 62 & - & 2.04 & VI \\
\hline Consider the benefit of adopting & 85 & 7 & - & 2.79 & II \\
\hline Consider how many of others have adopted it. & 56 & 40 & - & 3.63 & I \\
\hline Overall mean Score & & & & 2.66 & \\
\hline
\end{tabular}




\begin{tabular}{|c|c|c|c|c|c|}
\hline Overall Rank & & & & & $\mathbf{I}$ \\
\hline \multicolumn{6}{|c|}{ Table 2: Contd., } \\
\hline \multicolumn{6}{|c|}{ Preservation of Information } \\
\hline By memory & 89 & 11 & 00 & 2.59 & I \\
\hline Making write up & 27 & 54 & 19 & 2.08 & III \\
\hline By preserving collected material & 40 & 47 & 13 & 2.27 & II \\
\hline Overall mean Score & & & & 2.41 & \\
\hline Overall Rank & & & & & II \\
\hline
\end{tabular}

Regarding discussion method of evolution of information it was observed that family elders /friends/relatives were consulted to higher to medium extent (2.64weighted mean), while successful self employed women were consulted to medium extent (2.54) ranking 2nd. It may be to easy availability for consultation and evaluation of information. Traders were discussed never by majority of respondents with 1.28 weighted mean score ranked last. It can further be observed that surpanch and local leaders of Mahila Mandal were discussed sometimes by many of the respondents.

Among self evaluation methods, "consider the benefit of adoption 'was considered by 86 per cent of the respondents, followed by 'availability of inputs '(2.67). Consideration of the social and cultural compatibility of innovation was equally taken. It is apparent that most of the women (89\%) preserve the information by memory with weighted mean score of 2.59 ranked 1st about half of them were also found to be preserving information sometimes by making written notes with 2.08 weighted mean score the findings are in tune with Varma (1987) which state that memorizing is most used method for information preservation as it the easiest one. Once the information is acquired and processed, it needs to be preserved for further use.

\section{Information Output Pattern}

It was found that all the respondents had knowledge of availability of credit and higher number (76\%) of respondents were more prone to go to relatives followed by cooperative societies for credit. Regarding the knowledge about availability of input procurement,almost all the respondents were prone to go to relatives followed by cooperative societies for credit. Regarding the knowledge about availability of input procurement,almost all the respondents, respectively.

Table 3: Information Output Pattern of Tribal Women N=100

\begin{tabular}{|l|c|c|}
\hline \multicolumn{1}{|c|}{ Parameters } & Yes/No & Freequency* \\
\hline 1. Availability of credit for self employment & Yes & $\mathbf{1 0 0}$ \\
\hline Source of Credit & & 60 \\
\hline i). Bank & & 74 \\
\hline ii). Cooperative Society & & 23 \\
\hline iii). Traders & & 76 \\
\hline iv). Relatives & & 75 \\
\hline v). Land owners & & 25 \\
\hline vi). Voluntary agencies & Yes & $\mathbf{9 5}$ \\
\hline 2. Knowledge about availability of input procurement & & \\
\hline Sources of input Procurement & \multicolumn{2}{|c|}{} \\
\hline i). Traders & & 51 \\
\hline ii). Open market & & 63 \\
\hline iii.). Local market & & 49 \\
\hline iv). Whole sale market & & 26 \\
\hline v). Cooperative society & & 16 \\
\hline vi). Small scale industry & \\
\hline
\end{tabular}




\begin{tabular}{|c|c|c|}
\hline \multirow{2}{*}{\multicolumn{3}{|c|}{ vii). Voluntary organizations }} \\
\hline & & \\
\hline Knowledge to increase profit & Yes & 97 \\
\hline \multicolumn{3}{|l|}{ Ways to increase profit } \\
\hline i). Through receiving skills & & $63^{*}$ \\
\hline ii). Procuring inputs at subsided rates & & $39 *$ \\
\hline iii). Increasing productivity & & $92 *$ \\
\hline iv). Receiving training & & $31^{*}$ \\
\hline v). Improved marketing & & $70^{*}$ \\
\hline Knowledge of selling products & Yes & 90* \\
\hline \multicolumn{3}{|l|}{ Places of selling products } \\
\hline i). Traders & & $60^{*}$ \\
\hline ii). Open market & & $87^{*}$ \\
\hline iii). Local market & & $33^{*}$ \\
\hline iv). Cooperative society & & $20^{*}$ \\
\hline v). Village people & & $59 *$ \\
\hline vi). Voluntary agency & & $06^{*}$ \\
\hline
\end{tabular}

Further,it was observed that almost all (97\%) respondents had knowledge to increase the profit while (92\%)of them had made out that increasing productivity was the main way to increase profitability whereas 70 per cent of them had considered improving marketing as the best way of making profit regarding marketing,open markets were considered to be the best way of making profit regarding marketing,open markets were considered to be the best places for marketing $(87 \%)$,followed by traders and village people. But selling products to voluntary agencies was considered to be less money making way.

\section{Communication Pattern}

It is clear from Table 4 that information input and information processing was found medium in most of the cases i.e. 44 and 42 percent respectively however information output was low for most of the cases (40\%). The overall communication pattern was found high and medium by equal number of respondents (36\%),followed by low ( $26 \%$ ). The weighted mean score also indicate that all the aspects of communication including overall communication was of medium level.

Table 4: Overall Communication Pattern of Tribal Women $\mathrm{N}=100$

\begin{tabular}{|l|c|c|c|c|}
\hline \multirow{2}{*}{ Aspects } & \multicolumn{4}{|c|}{ Scores } \\
\cline { 2 - 5 } & High (3) & Medium (2) & Low (1) & Weighted mean Score \\
\hline Information Input & 19 & 44 & 37 & 1.82 \\
\hline Information Processing & 28 & 42 & 30 & 1.98 \\
\hline Information Output & 22 & 38 & 40 & 1.82 \\
\hline Overall Communication & 36 & 36 & 26 & 2.06 \\
\hline
\end{tabular}

The findings of Kayshik(1994) are not in tune with results who reported unsatisfactory overall communication of rural women with below average means Table 5 indicates that participation of respondents in farming was positively and significantly related with communication pattern.

\section{CONCLUSIONS}

Information input can be inferred that non institutional sources were highly utilized for acquiring information. Regarding information processing self evolution was the most used method The utilization of information was high as all 
the respondents had benefited from the information received Information output pattern was low showing the need of government to act in spheres of credit /loan and marketing to help tribal women workers. There is also a need for institutional cosmopolite sources like village level worker, health assistant etc.to play role so that tribal women may use them as information inputs. Skill information and skill upgrading programme should be held for training entrepreneurs.

\section{REFERENCES}

1. Sigh, K S.1991. Status of Tribal's in India Primary Census Abstract for General Population, Scheduled Castes and Tribes.1971-1991.

2. Seema, 1990. Study on The Communication of Home and Farm Information Amongst Rural Women (unpublished)PhD.Thesis, Agricultural University, Haryana.

3. Rashid, M,M., Mondol,A,S., Rahman,M,S., and Noman,M,R,A,F.(2015). Use of Communication Sources by the Women Beneficiaries of RDRS in Income Generating Activities, International Journal of Agricultural Extension vol-3,Iss-3,pg no. 187 194

4. Kaushik, S.1994. Rural Energy Management for Human Resource Development a System's Approach PhD. Thesis, Agricultural University, Haryana..

5. Dhanasree, K., Vijayabhinandana,B., and Pradeepkumar,P,B.(2014). Socio-Economic Empowerment of Tribal Women in High Altitude and Tribal Zone of Andhra Pradesh. International Journal of Innovative Research in Science, Engineering and Technology. Vol. 3, Issue 2, ISSN: 2319-8753.

6. Varma,U.1987. An Analysis of Communication Pattern among the Information Generating, Information Disseminating and Information Utilization System of Home Science in Haryana (unpublished) Ph.D.Thesis Hary Agri Univ Hisar. 